\title{
TEACHING SUSTAINABILITY IN TOURISM EDUCATION: A TEACHING SIMULATION
}

\begin{abstract}
Addressing the dearth of sustainable tourism teaching simulations, this article details the design, development, testing and validation of a destination development game simulation designed to reinforce the teaching and learning of sustainable tourism principles. We discuss two stages of model development, including an earlier game developed using system dynamics and an evolved version with agent-based modelling extensions, incorporating a flock leadership framework and network theory, which together provided a framework for considering the human dynamics provoked within the simulation interaction. For Study 1, simulation validation was based on feedback received from staff and students of an Australian higher education institution for which students were assessed on their use of the simulation in a classroom setting. The simulation illustrated to the students the complexity of decision-making in tourism destinations, while highlighting the need for a broader range of stakeholder interactions. We detail the initial validation of Study 2 as a precursor to further testing. The development process has highlighted the importance of a coherent and familiar context as background to using such a simulation as a teaching and learning tool. Further validation will be conducted in diverse institutions to trial and observe different modes of uptake of the simulation.
\end{abstract}

Key words - simulation game, system dynamics, agent-based modelling, sustainable tourism 


\section{Introduction}

We detail the design, development, testing and validation of a simulation game to reinforce the teaching and learning of sustainable tourism principles. The game is specifically designed for undergraduate tourism and hospitality students, in contrast to the majority of business game simulations, which are targeted at experienced managers or final-year postgraduate business degree students. The simulation game aims to support educators to encourage students to apply learning and theories to understand how sustainable practices can have substantial outcomes for tourism and hospitality stakeholders. The game also aims to enable students to gain a deep and practical understanding of the concept of sustainability and its critical and global importance though experiential learning (Kolb, 1984).

Taking a frequently cited definition, the concept of sustainable tourism is "tourism that takes full account of its current and future economic, social and environmental impacts, addressing the needs of visitors, the industry, the environment and host communities" (UNWTO, 2013, p. 10). This definition reflects the traditional triple bottom line framework and the three pillars of sustainability, which encompass the economic, socio-cultural and natural/ecological environments, colloquially known as the three Ps (prosperity/profit, people and planet). The perspective is also broadly reflected in the 17 universal Sustainable Development Goals (SDGs) announced by the United Nations in 2015 (United Nations, 2015) to ambitiously drive the agenda for global sustainable development towards 2030.

Notwithstanding available definitions and frameworks, sustainability principles in regards to sustainable tourism remain contested and debated with their paradoxical focus on development, which implies growth (Cotterell, Hales, Arcodia \& Ferreirato, 2019). Moyle, McLennan, Ruhanen and Weiler (2014) tracked the concept of sustainability as it was articulated in Australian tourism strategic planning and policy documents (published between 2000 and 2011) and identified a shift in the conceptualisation of sustainability from naturebased, social and triple bottom line concepts toward a focus on climate change, responsibility, adaption and transformation, which is reflective of deeper and more nuanced understandings of sustainability.

For destinations, sustainable tourism involves multiple levels of stakeholders whose needs and wants must be taken into consideration in tourism visioning, planning, development, management and marketing. Multi-stakeholder perspectives of tourism communities can include visitors, central government, local government, public policy makers, destination planners and managers, tourism entrepreneurs and business operators and their staff, as well as local communities including residents, special interest groups and indigenous traditional owners of the land. Membership within these groups can blur, where an individual may belong to several, and sometimes conflicting, stakeholder groups and may hold different views depending on the context. All parties interact within a larger socio-economic and political context, and in this way, tourism can be viewed as a complex adaptive system (Schianetz \& Kavanagh, 2008) of highly diverse stakeholders affected by macroenvironmental forces (Leiper, 1998), including politics and power dynamics. These relationships evolve and change as a result of various conflicts and pressures; static models therefore present challenges when educators want to demonstrate how decisions made by one party may have significant implications for another.

To understand complex whole systems, systems thinking has been defined in a sustainability context as comprising internal relationships amongst elements of a system and external relationships between a system and its context (Phelan, McBain, Ferguson, Brown, Hay, 
Horsfield \& Taplin, 2015). The diversity of relationships and interrelationships in such systems exemplify the non-linear change, uncertainty, and potential for evolution and contestation amongst stakeholders (Gössling, 2017; Phelan et al., 2015). Changes implemented to tourism systems may also produce contradictory implications for social, economic and environmental sustainability (Gössling, 2017). The inherent complexities of sustainable tourism can be examined using a systems thinking approach, which focuses on the dynamics of a system, starting from simpler causal loop relationships and combining them to form more complex systems.

Tourism academics have called for educators to impart the notion of 'strong sustainability' as research suggests that tourism students are graduating with narrow understandings of sustainability. Cotterell et al. (2019, p. 884) contend "further research is essential in order to advance knowledge on how tourism educators can equip graduates with ways of thinking critically, systemically and holistically about how a stronger, more holistic sustainable tourism industry can be generated over time and thus assist with achieving the SDGs by 2030". Tourism and hospitality educators play an important role in combatting narrow ideas of sustainability, whereby only visitor growth, expenditure, earnings and other economic metrics have been used to measure success. Yet while higher education providers strive to demonstrate the practical realities of sustainable tourism management, doing so can prove challenging in the classroom environment (Boyle, 2017), which can feel removed from the 'real world' outside the lecture hall or tutorial room. This simulation therefore provides a technologically-driven response to Benckendorff, Sheldon and Fesenmeier's (2014) call for information technology to contribute to the constant education that is key to encouraging tourism sustainability.

This paper is divided into two distinct but sequentially-linked stages of research regarding the development of the simulation game model based on systems thinking, which was developed to promote students' strong understanding of sustainable tourism management as well as its meaning and implications for various stakeholders. To maintain a parsimonious model, factors modelled are mostly aligned to the economic and environmental pillars of sustainability. However, the social dimension is accounted for by the interplay of these factors operating within a social network. In consideration of the global SDG framework, the simulation is primarily associated with Goals 8 (Decent Work and Economic Growth), 9 (Industry, Innovation and Infrastructure), 11 (Sustainable Cities and Communities), 12 (Responsible Consumption and Production) and 17 (Partnerships for the Goals). More broadly, there are potential linkages to each of the 17 Goals, reflective of the complex network they represent in which each goal is linked to every other goal (albeit, at different strengths and path lengths) (Le Blanc, 2015).

Each study contains a review and critique of the relevant literature, an overview of that version of the simulation, the methods used to test and validate it and also discussion of the findings. Study 1 addresses an earlier game developed using system dynamics (SD), which was validated using feedback received from staff and students at an Australian higher education institution. Study 2 presents the initial validation of an evolved version of the simulation game, with agent-based modelling extensions to a SD core based on Will's (2016) flock leadership framework, which was incorporated to model emergent collective behaviour in the game. The initial and evolved versions extend the limited published tourism simulations by accommodating dynamic changes in the scenario and accounting for interaction effects between key destination stakeholders, such as the way in which stakeholder views on specific destination development proposals change dependent on their interactions with other parties within their immediate (and constantly changing) social network. The conclusion of the paper integrates the two stages together by outlining practical implications, ways to overcome challenges associated with the simulation game from a teaching perspective, limitations to the research, opportunities for future research and the next steps in the development of the simulation game moving forward. 


\section{Study 1}

\subsection{Literature review}

Simulations, as a form of role-play, are designed to provide students with opportunities to participate in realistic decision-making without the associated risks (Douglas, Miller, Kwansa \& Cummings, 2008). This learning tool has enjoyed a surge in popularity in recent years as it allows students to enhance employability through the application of critical thinking and decision-making skills (Benckendorff, Lohmann, Pratt, Whitelaw \& Reynolds, 2015).

Simulations involve and engage students in ways that supplement lectures, resulting in active experiential learning that is beneficial to students (Singh, Mangalaraj \& Taneja, 2010). Experiential learning encourages better learning outcomes by creating environments of immersion, interaction and complexity (Schott \& Marshall, 2018). Simulation games have long been used as learning aids in business education, see, for example, Gosen and Washbush (2004). Despite their popularity as supplementary learning aids, there is a surprisingly limited number of off-the-shelf pedagogical software solutions available. The more popular, such as Markstrat (Larréché, Gatignon, \& Triolet, 2010) and The Business Policy Game (Cotter \& Fritzsche, 2010), are designed predominantly for experienced managers or final-year postgraduate business degree students. Such simulations are complex and often rely on an advanced level of knowledge and experience that makes them unsuitable for use in subjects designed for undergraduate students. While there is an array of simulations available for business education, many of them focus either on organisation-based business management or specific business functions, such as marketing (OLT, 2017b).

Within tourism and hospitality, the aforementioned focus on management and specific business functions has translated into a number of simulations concentrating on hotel, airline and restaurant management. Such simulators include HOTS and RevSim (hotel management simulators), and AIRLINE Online (airline management simulator), and typically focus on revenue, pricing and inventory management as their objectives. Similarly, the predominance of simulations for specific business functions manifests itself in tourism and hospitality as function-specific simulations, such as the use of marketing or corporate social responsibility simulations as supplements to lectures (OLT, 2017a). These simulations have generally been integrated into postgraduate courses, with some used at undergraduate level in third year or capstone subjects (OLT 2017a).

The lack of tourism focused simulations is an opportunity where our current simulation seeks to contribute. We note, however, a study by Anctil and Le Blanc (2016) that made some progress in this area. Anctil and Le Blanc's (2016) educational simulation of coastal tourism in a developing country detailed a SD model of tourism development. The simulation accommodates the competing interests of hotel developers, central government, local residents (as represented by local government) and a community of indigenous fisherman whose livelihoods are dependent on local fishing stocks. Acknowledging the contested nature of tourism investment decisions based on stakeholder interest, the simulation recognises the "political economy of decision-making" (Anctil \& Le Blanc, 2016, p. 784).

The coastal simulation runs over a 20 -year period, with the base scenario involving a resort development that results in an influx of tourists and income, an increase in solid waste and waste water proportional to tourist numbers, which is untreated (dumped in landfill, effluents unprocessed). The resulting feedback of the model sees a decrease in fish stocks and a 
decrease in tourist numbers over time as the destination becomes increasingly polluted. The necessary intervention in Anctil and Le Blanc's (2016) simulation to circumvent the negative impacts of tourism development is investment in water and solid waste treatment facilities. While innovative in its use of SD, this coastal simulation has several weaknesses: the simulation scenario is static, it does not take into account interaction effects between stakeholders, and is pitched at an audience with established knowledge of the industry, such as industry practitioners. The scenario learning approach is also not validated using empirical research. These concerns are variously addressed in the two versions of the simulation that are the key focus of this research.

\subsection{Simulation overview}

Our overall objective is the construction and evaluation of an automated simulation game designed to assist in the teaching and learning of sustainable tourism principles and strategies. This simulation builds on an earlier game aimed at introductory-level students developed using SD principles and software (Maani \& Cavana, 2000). SD may be thought of as a practical operationalisation of 'systems thinking' which is one approach for developing a topdown, holistic view and understanding of a complex problem domain (Senge, 1990). SD was hence chosen as it enabled modelling of a range of potential outcomes based on the dynamic interactions of multiple tourism stakeholders aligned to the principals of systems thinking. The availability of easy-to-use, modelling and simulation software tools also made it an attractive option for use in sustainable tourism education. Following on from this SD approach, simulations were modelled initially as causal loop diagrams (CLDs), which are used to visualise and specify the interrelated nature of variables in a system (very often by key stakeholders and decision makers), and then implemented using an off-the-shelf, commercial SD development software, Powersim. All models and designs were specified by the research team. An iterative development, prototyping development methodology (Pressman, 2005) was employed, such that enhancements were applied after each trial of the software. The initial version was developed and trialled in 2015 and enhancements are ongoing in 2020.

The use of games and network theory in education has evolved exponentially with the use of information technologies and game programming. However, the lack of connection between these and learning theory has been criticised. Wu et al.'s (2012) meta-analysis of extant games studies confirmed a lack of stated incorporation of learning theories in learning game design. The foundations of game-based learning cannot be understood by taking any single theoretical approach to learning (Plass, Homer \& Kinzer, 2015). In our study, we used the Australian Qualifications Framework - Australia's national policy for regulated qualifications in education and training (AQF, 2013) - as the template to provide guidance for the ongoing design of the simulation. The national education framework incorporates a number of learning theories in its guidelines for the design of courses and programs relative to various qualification levels (AQF, 2013).

In the simulation, students are divided into syndicates playing the part of Destination Management Organisations (DMOs). They are required to manage green economy (GE) and tourism development (TD) investment decisions in the destination, plus decide on how much land should be rezoned from protected/rural to industrial/business/residential. The total simulated game time is 20 years, divided into four five-yearly segments and with each simulation step equivalent to one year. Students receive reports on performance at the end of each five-year segment and then make decisions on investment and land rezoning for the next 
five-year period. Performance is determined by net profit, visitor numbers and other key indicators such as environmental health and overall region attractiveness at game's end.

At its core, this first stage of simulation development uses SD to produce outcomes relating to decisions made by students. The resulting CLD includes various factors that are either determined by the student or influenced by preceding factor(s). The interrelationships between these factors are represented in Figure 1.

\section{- Insert Figure 1 here -}

With reference to the terms used in the above figure, visitors produce revenue, which generates TD (Tourism Development) expenditure for destination development. Too much destination development leads to a decline in destination quality, which will, in turn, negatively affect environment quality and destination attractiveness. If destination attractiveness declines too much, visitors will cease to arrive and this completes the core (balancing) feedback loop of the system. The decrease in environment quality can be mitigated to some extent by investing in $G E$ (green economy) expenditure, akin to Anctil and Le Blanc's (2016) simulation. There is an additional sub-model, which deals with land use: specifically, as destination development takes off, more land will be required for tourism development. If too little land is rezoned for development, the lack of infrastructure will cause visitors to stay away; conversely, if too much is rezoned, this will eventually add to environment despoilment.

\subsection{Methods}

This simulation was first presented to full-time academic teaching staff for feedback at an Australian higher education provider of tourism and hospitality degrees. Sustainability concepts are taught across various degrees of the institution; hence all teaching staff were invited to participate in the study. Feedback regarding possible improvements to the simulation was sought in August 2016, comprising three areas - directions in which the simulation could be extended, suggestions for improvement, and the value of the simulation for improving student learning. Following a demonstration led by the development team ,12 staff provided this feedback in the form of written comments on a number of functional elements of the game.

The initial version of the simulation was also evaluated in a classroom setting towards the end of the teaching period (semester two) during August 2016 in an introductory undergraduate tourism and hospitality subject, Destinations and Attractions, which was offered as part of a Bachelor of Tourism and Hospitality Management degree. A total of 12 groups of students ( $\mathrm{n}=52$ students) participated across four two-hour tutorials that were held in one week of the semester as a once-off activity. The simulation was discussed prior during a lecture on sustainable tourism so that students were introduced to the underpinning tourism development and planning theories and concepts before partaking in the simulation. Contextualising the game, groups of students working in teams of four or five, assumed the role of a DMO for Ballarat, a regional tourism destination in Victoria, Australia. Students were asked to make decisions regarding GE and TD investments, and in relation to the rezoning of rural lands. They were given four five-year segments (a total of 20 years) to make GE, TD and rezoning decisions for the destination, with discussions in between segments to allow groups to evaluate the outcomes of their input decisions before deciding on and running the next set of inputs into the subsequent five-year segment. The trial led to a range of simulation outcomes and feedback post-gameplay. At each stage, decision group's inputs and 
resulting outputs were projected on a large screen, allowing fellow classmates insight into the different gameplay strategies and their attendant outcomes.

The students were then invited to complete a short-written survey, elaborating on their gameplay experience and how the simulation contributed to their understanding of sustainability concepts and impacts of their decisions on the simulation destination. They were also asked to provide suggestions for improvement to the design and learning experience of the simulation. After completing the survey, a debrief discussion was also held during the tutorial class in which students related their learnings to the theories introduced in the lecture. The teachers administering the exercise observed the reactions of the students to the simulated outcomes and recorded notes of these experiences. These notes were collected at the end of the exercise and compiled for analysis.

All qualitative data were analysed manually using inductive thematic analyses to provide maximum interpretation of these user experiences (Boyatsis, 1998). These themes were verified by an additional member of the research team to explore congruence among coders. Themes relating to the gameplay experience were used to inform the development of Study 2 and generally came from student and academic teaching staff responses. While student responses were used to ascertain the influence of simulation gameplay on their understanding of sustainable tourism concepts, staff feedback also provided suggestions for making the simulation more relevant to their current subjects or means by which their subjects could leverage off the simulation to promote in-depth understanding of sustainability concepts. The results of this analysis are discussed in the next section.

\subsection{Study 1 Results and Discussion}

Most students not only noted an improvement in understanding of concepts that were taught previously, but also outlined ways in which their understanding was improved. In particular, some appreciated being able to see the impacts of small changes in inputs on measurable outcomes relating to destinations, supplementing the knowledge taught in the subject. They also developed a greater understanding of the variety of factors involved in decision-making ("That it is difficult to balance both tourism development and being susintable (sic) because there are a lot of variables to think of" - student 13 / "The simulation game has demonstrated to me that in order to have an increase on the tourism revenue, it is necessary to invest in social and environmental factors, by doing this it would generate a balance on the distribution of the resources" - student 37). Some students were surprised that investing in development did not result in short term profits, thereby highlighting the complexity of the tourism system ("We did invest (to both green economy and tourism development) after dropping all the development. However, it didn't rise (sic) the revenue as much as we expect. Probably, it will take long to get more revenue" - student 42 / "It has given me an understanding the product life exists and needs careful planning for the years to come. Decisions need to be made across the whole board. Destination development takes a lot of time, investment, maintenance of all economic sustainability is important" - student 50)

In addition, the students noted that the varied outputs showing impacts of their decision making on the destination's annual revenue, visitor numbers, and destination attractiveness gave them a clearer picture of the multiple outcomes that needed to be considered ("Make me understand the different components that affect a destination's attractiveness, profit and visitor numbers" - student 24 / "Increase in revenue and visitors doesn't benefit long term if you don't consider the green economy factor as well as land rezone." - student 29). Academic teaching staff who ran the tutorials observed students' reactions of surprise when 
employing a strategy of maximising all investment spending and land release that did not result in positive and sustained outcomes for the destination. Such surprisingly negative outcomes from what was perceived to be maximisation of resources served as impetus to spur students on to consider the varying levels of influence each decision had on the overall outcome.

As a corollary, staff generally anticipated that the simulation could provide a good starting point for more in-depth discussions with students ("Hopefully there would be an understanding that complexity exists rather than any specific lesson of the preloaded cause and effect results" - staff), and appreciated the chance it gave to students to make destination management decisions with no personal risk or penalty ("Learn from mistakes [simulated] before learning from financial losses" - staff). There was also the expectation that the simulation could be utilised in alternative teaching media, such as online delivery, to enhance students' understanding of the complexity associated with managing destinations. Extending the application of the simulation into other related areas such as events or gastronomy scenarios was also proposed as alternative uses.

The suggestions from both staff and students for improving the simulation were sorted into three broad categories - game context, design and outputs. Regarding game context, key themes that emerged related to improved contextual clarity and additional supports required for gameplay. In this respect, students asked for more details on the background of the destination they were managing ("Having PowerPoint to have more details and information. So that we can look back to the PowerPoint if we don't understand" - student 47 / "More case studies at the start to help students understand the broad array of factors that influence sustainable destination decision making" - staff). A key suggestion to facilitate better user experience was a step-by-step guide to ease users into the simulation through videos, discussion and illustrated prompts ("Perhaps a video example. Include some scaffolding exercises so students can work at own pace”- staff). This pacing was particularly relevant for students who did not understand what constituted GE and TD spending, or were unfamiliar with economics in tourism systems.

In relation to game design, the key themes focused on technical design, adequacy of control and the importance of including a range of stakeholders, with both students and staff commenting on the simple graphics and design of the simulation, suggesting that these could be enhanced with more colours and a less intimidating design ("More visually stimulating/less 'Maths' visuals" - staff). Furthermore, there were suggestions that the sliders which were used in the simulation's graphic interface for determining GE and TD investments, as well as land rezoning percentages, lacked accuracy, and that more precise forms of input could improve the experience ("Maybe make the statistical input system a bit more accurate. So that exact percentages can be inputted"-student 33).

Another suggestion was to incorporate multiple perspectives into the simulation, such that the sentiments of stakeholders other than DMOs would be captured ("Considering more than one decision maker to reflect the real nature of 'DM' at destinations" - staff). Feedback also suggested that the simulation consider promotions and their related outcomes, as it would provide students with an indication of which promotional strategies were more effective. There were also suggestions to include other inputs in addition to the existing three in Version 1, to more accurately model reality. These included: ethical considerations, transport link impacts, acts of terror and natural disasters, the socio-economic profiles of visitor markets, political and legislative upheaval, and innovations. 
Lastly, the themes that led to suggested output improvements indicated the need for interpretive assistance and greater alignment with curricula. A key suggestion was to increase the amount of detail provided if used as a learning tool. Some users noted that while graphs and numbers were illustrative, more explanation was required to interpret the consequences of these outputs for those who were still at the beginning stages of their academic study ("Information provided to explain the results, not simply the results graphed" - student 38). Other suggestions were to align results to theories and models that were being taught in the introductory subject ("Could help students 'connect the dots' between theory \& practical application” - staff), such as Butler's (1980; 2006) Tourism Area Life Cycle (TALC) model or Leiper's (1998) Tourism System theory.

Collectively, these findings suggest that students achieved the intended learning outcomes for both the subject and the simulation. Namely, these included being able to articulate the principles and practices involved in developing and operating sustainable tourism destinations, identifying key stakeholders involved in the planning, development and management of destinations, as well as understanding economic, environmental and social issues that impact tourism destinations.

As game design was central to designing and improving the context and outcomes of the simulation, the research team embarked on an enhancement strategy underpinned by agentbased technology and design methods. This enhanced version adopted a multi-stakeholder tourism destination community, where decisions made are consistent with a power-political theoretical perspective, akin to Anctil and Le Blanc's (2016) work. In consideration of this multi-stakeholder perspective, a brief coverage of the literature on power and politics is discussed in the following section.

\section{Study 2}

\subsection{Literature review}

There is an established tradition of research into the impact of power and politics on decisionmaking within and beyond organisations. Traditional views of these concepts (i.e., power and politics), suggest that power is primarily concerned with dependence: i.e., if party $B$ is dependent on party $A$, then $A$ has power over $B$ (Emerson, 1962). Pfeffer's (1981) work is particularly supportive of this approach. By assessing power sources such as control over provision of resources, expert knowledge and position in the communications network, it is possible to quantify parties' levels of power.

A recent meta-analysis on learning in groups (Koeslag-Kreunen, Van den Bossche, Hoven, Van der Klink \& Gijselaers, 2018) found that leaders who focussed on people encouraged team learning for both adaptive and developmental tasks, whereas task-focussed leaders influence team learning for adaptive tasks only. In our work, the scenario is designed with staged developmental tasks, however, adaptivity is required as a result of the learning context and student roles.

In developing the simulation, we drew on network theory which provides representation of symmetric or asymmetric relations between discrete objects through graphing, connectivity, topology, robustness and significance (Newman, 2010). The theory informed the simulation design elements to describe and explicate (graphing) the elements of the system, mapping the 
relationships among them (connectivity), viewing the structure of the network (topology), and for assessing the fragility and resilience of the network (robustness) in response to changes in any element. Applying network theory to the development of a teaching and learning simulation underpinned by SD provided a cognitive framework and tools for understanding organisations as interrelated dynamically changing systems (significance). We have attempted to model that complexity of interactions among elements of the system in the design. In the current age of mathematically modelling phenomena, network theory has been increasingly incorporated in the analysis of SD across diverse disciplines (Borgatti \& Halgin, 2011; Salancik, 1995).

Drawing on the network perspective, leaders whose advice was valued resulted in teams which had lower conflict and stronger team viability. By contrast leaders who had advice ties with subordinates had higher levels of conflict and lower team viability (Balkundi, Barsness \& Michael, 2009). In a similar setting, a recent study of leadership in student role plays found that group leaders who had more positive advice ties and fewer negative avoidance ties were more likely to be recognised as leaders by their followers (Chiu, Balkundi \& Weinberg, 2017).

Network and diffusion researchers typically use social network analysis (SNA) to observe the diffusion of ideas and have observed the effect of social contagion in the spread of innovation. Social contagion (Hodas \& Lerman, 2014) concerns the propagation of ideas, emotions, values, beliefs and behaviour patterns through imitation and conformity within groups. The concept along with behavioural contagion has been studied using SNA in a range of contexts including health, politics, and moral panic in societies and marketing (see for example, Barsade, 2002). This understanding is consistent with a substantial body of research indicating that: i) individuals tend to conform to the dominant political beliefs and values of their peer group just as they do with other social norms (Suhay, 2016) and ii) too much pressure to conform politically may have precisely the opposite impact.

Taken together, the above observations suggest likely mechanisms operating in our scenario so that opinion leaders will shape behaviour of others where they are strongly positioned sociometrically and where appropriate approaches to use of power and influence are deployed. However, such interactions are dynamic and could change readily depending on challenges and strategies used by either followers or leaders.

In light of these dynamic changes, we draw on recent work by Will (2016) who used agentbased $(\mathrm{AB})$ modelling of interactive and dynamic behaviour to test a framework for flock leadership. Flock leadership occurs as part of the phenomenon of both convergent and divergent collective behaviour, which is enacted in emergent situations in response to reality, such as interacting and working though challenges. Will's (2016) AB flocking model represented these interactive dynamics and emergent processes in groups where there were no formal leaders to exert power. Agents autonomously make their own decisions though they are interconnected in the collective so that decisions are contingent on peer behaviours; therefore, behaviour may fluctuate between converging and diverging in relation to new information. Will (2016) theorised that the flock leadership framework can usefully explain emergent collective behaviour in groups and applied his framework to a number of hypothetical scenarios.

Version 2 of the simulation utilises this flocking model to inform on parties' voting intentions on various destination development issues. In this model, we contend that each party in the 
simulation will tend to vote similarly to those in their immediate social network, just as birds might fly in the same direction as those around them. Though, analogous to veering in the flocking model, if pressure to conform exceeds a threshold level, parties may rebel and vote differently.

Given that stakeholders and conflicts between them are critical, it was imperative that we were as precise as possible in defining the concept of the tourism "community" and its constituent stakeholder groups. As noted earlier, in their SD simulation, Anctil and Le Blanc (2016) used three stakeholder groups: the central government, local government and an indigenous community group. However, Bowen et al. (2016, p. 4), in their study on politics, power and tourism development in the Maldives, nominate four groups: government, tourism entrepreneurs, the local community and non-government organisations (NGOs), but also observe "that each stakeholder group is somewhat porous". That is, stakeholder groups overlap and, given that parties may have different goals and views when wearing different hats, this overlap would appear to be extremely important. We contend that we can substantially improve our understanding of this concept (stakeholders and stakeholder group overlaps) by utilising one or more of the conceptual modelling techniques commonly employed in information systems and software engineering research. Specifically, we use the "entity-relationship" (ER) modelling formalism of Chen (1976) and, more precisely, the "resources-events-agents" (REA) variant of McCarthy (1982).

In this multi-stakeholder ER model underpinning the engineering of Version 2, parties are related to other parties in party-party involvement relationships with one (and only one) role associated with each relationship. Examples of these roles are employs, works for (the inverse of employs) and subtype, which is used to specify the breakdown of the community into its constituent stakeholder groups.

The major community (party) groupings we employed were community business owner/operators, community resident employees and community resident non-employed individuals, government and Green Economy Advisory Committee (GEAC, comprising NGOs and other destination stakeholders). All members of these agent groups have an annual income and a development attitude. Business owner/operators are predominantly prodevelopment; non-employed residents are mildly anti-development; and employees tend to swing more between the pro-and anti-development views than the other parties. Notably, all parties are sensitive to environmental and income shifts, and that sensitivity influences both their general development attitude and their attitudes to specific tactics.

Resources can be anything that agents in a tourism destination might utilise, ranging from natural resources to a business enterprise such as a hotel. Resources (similar to parties) may be related to other resources in resource-resource-involvement (rri) relationships. Resources may also be linked to parties in party-resource-involvement (pri) relationships. These may be interpreted as activities, ranging from a tourist "staying" in a hotel to a DMO being "responsible for" a destination (a mega-resource).

By linking these activities to the eventual goals of the destination, the array of involvements between parties, resources and goals facilitate flocking behaviour in the simulation model. We noted earlier how agents' voting intentions are influenced by those around them; specifically, agents will vote consistently with those in their immediate social network unless a neighbour gets too close (possibly resulting in a vote opposite to that of the overall local group view). Therefore, this model modifies the simulation in two critical ways: (i) it allows 
for an almost infinite expansion of the simulation depending on data available for the destination, and (ii) it facilitates the separation of overlapping stakeholder identities to generate multi-stakeholder activities and consequent outcomes. In the case of this simulation, each stakeholder identity (party) may exhibit vastly different attitudes towards available tactics (activities) based on the current destination state, decisions made for the destination in the immediate past and current income levels. As noted, many organisation and management theory researchers have emphasised that power is less about individuals and more about relationships between them (Pfeffer, 1981).

\subsection{Simulation overview}

With a view to introducing additional decision-making complexity and more realistic problem scenarios, AB modelling (through ER models) was applied to Version 2 of the simulation to accommodate further intelligent and goal-directed behaviour, and to allow for role-based differentiation of goals for categories of individuals. As such, the enhanced game employs the dual-paradigm AB + SD approach espoused by Borshchev and Filippov (2004). Whilst SD allows a complex system to be modelled using a top-down approach, in contrast, the $\mathrm{AB}$ approach allows detailed attribute information to be specified at the individual agent level and for system behaviour to emerge from the interactions of agents during the simulation. Borschev and Filippov (2004) argue that both approaches are complementary and provide detailed guidelines on how to combine them, not discussed here for brevity sake.

As such, the simulation is informed by the Will's (2016) flocking model within a wider organised anarchy framework (Cohen, March \& Olsen, 1972). This version also builds on the Greta tool of McGrath and More (2001), which involves different stakeholders with conflicting objectives and is underpinned by a dynamic social network specifying the strength of connections between stakeholders and amongst groups of stakeholders. Therefore, our research also utilises and adds to the growing body of literature dealing with the use of SNA in tourism and hospitality studies, such as Scott, Baggio and Cooper (2008).

In Version 2, players again adopt the role of DMOs and need to balance the conflicting goals and objectives of different tourism stakeholders while making decisions on tourism development, green economy investment and land rezoning. The extended model and simulation though, have been designed in a way that allows for various types of extensions depending on pedagogical objectives (for example, with a hospitality, tourism or events focus). This approach allows for future extensions where decisions are much more focused, for example, on new hotels of particular types, waste and water treatment plants, reforestation and infrastructure renewal. In addition, with all possible extension types, decision outcomes are now uncertain; players compete against other players who also play the part of DMOs and against virtual agents in all stakeholder categories and all of these have their own, oftenconflicting objectives. Stakeholder ties are strengthened or weakened depending on decision outcomes and tie-strength is, recursively, a major determinant of future decision-making outcomes. Consistent with the garbage can model (Cohen et al., 1972), luck plays a part in outcomes, with emergent behaviour partly contingent on the right sets of agents, problems and solutions coming together at the right times (choice opportunities).

Students are assigned to syndicates. As with the original version, the game runs for a 20 -year period but the newer version requires syndicates to make decisions related to various investment options at 2-yearly intervals. Additionally, as with the original version, performance is based on annual revenue, destination attractiveness and environmental health. 
If syndicates make purely strategic decisions, this does not necessarily lead to the desired action automatically ensuing: instead, the destination community "votes" on each decision made and an unfavourable outcome results in the status quo rather than the specified new parameters being applied. A successful vote improves the credibility of the DMO (i.e., game players) and a negative vote does the opposite. DMO credibility is one important determinant of vote success with another factor being the results of the way agents flock around the model world and the consequent underlying structures of the community social network.

Effectively, the values chosen implicitly amount to a decision to invoke various political tactics, which may succeed or fail, dependent largely on overall community attitude to development, the structure of the underlying social network and, critically, the (influence) power of those parties chosen to participate in the GEAC, which plays a pivotal, mediating role in the success of GE investment. Tactical options available to players are: i) establishment of a GEAC; ii) regional development promotion; iii) GE development; iv) tax breaks for business; v) tax breaks for GE investment; vi) rural and protected land release for development; and vii) incentives for business transformation. Before discussing this further, we need to outline some important characteristics of the game destination.

\section{Destination overview}

In response to Version 1 feedback, the game context was enhanced in this later version. The game destination is based upon the Gippsland Lakes tourism region in eastern Victoria, Australia. The destination has a population of approximately 20,000 , of whom roughly $50 \%$ are employed in some 500 business enterprises, which includes 60 hotels/motels, with an average of 31 rooms each and an average room-nights occupied (RNO) figure of $47.0 \%$ (Tourism Victoria, 2015). 4.3 million tourists visit the region annually and 1.8 million of these are overnight visitors, with an average length of stay of three days and an average expenditure of $\$ 117$ per day (Tourism Victoria, 2015).

The developed destination is home to Australia's largest inland network of waterways. It is extremely popular with young families (most of whom camp or stay in caravan parks) during the summer vacation months and its activities and attractions include beaches, swimming, surfing, lakes exploration via kayak, paddleboat or hire-cruise, bushwalking, cycling, fishing and a variety of restaurants featuring local seafood and other cuisines (Visit Victoria, 2017). Twelve per cent of visitors fish, making the destination one of the most popular recreational fishing spots in the entire State of Victoria (6\% average for all regions). Stocks of the more popular fish species though, have dropped to alarmingly low levels recently and it appears this is due, in large part, to commercial fishing and trawling operations. Solutions suggested include a complete ban or severe limitations on commercial fishing (Barr, 2015). Commercial fishing, however, is a major contributor to the local economy and, given that the region is somewhat stagnant in terms of the TALC (Butler, 1980, 2006), with an annual growth rate of $1 \%$ (compared to $6 \%$ for the rest of Victoria), there is an understandable reluctance to impose such limitations. This real and unresolved dilemma, involving the delicate balance between the economic and environmental wellbeing of the region, makes the destination an ideal context for a sustainable tourism simulation game such as the one described here.

\subsection{Study 2 Methods and Initial Results}

Validation of the full AB simulation is an ongoing process and, since design and development are based on a prototyping approach, system testing is necessarily iterative (Pressman, 2005). An intrinsic feature of this information systems construction method is that there is no fixed end-date: i.e., improvements and enhancements will continue to be made, as the result of trial participant feedback, following every future trial. Arguments for this as a 
valid research approach have been put forward by Hevner, March, Park and Ram (2004) and Gregor and Hevner (2013) among others. Validation at each functional enhancement iteration broadly involves: i) desk checking, to ensure that simulation behaviour is, to the extent possible, 'sensible'; and ii) classroom validation, aimed at establishing the extent to which the game supports, reinforces and enhances traditional teaching and learning methods (lectures, tutorials, exercises and assignments).

Desk checking evaluates the impact of different combinations of investment and other decisions on key dependent variables (revenue, development level, destination attractiveness, environment quality, land use, overall development attitudes and GEAC influence). An example of some test output is presented in Figure 2. The graph illustrates how annual revenue varies with (GE/total) investment ratio (IR) patterns over the full course of the simulation.

\section{- Insert Figure 2 here -}

With IR2, GE investment remains at $10 \%$ for the duration of the simulation and annual revenue begins to drop at around Year 12 indicating, perhaps, that the investment ratio is too low. With the other pattern, the IR increases from $10 \%$ to around $40 \%$ at Year 20 and revenue figures rise steadily at the same time. This interpretation makes sense given that while GE investment is important at all stages of the destination life-cycle, more effort and funds are needed to protect an already, well-developed destination from the negative environmental and social consequences of further development (Butler, 2006; Morrison, 2013).

\section{Conclusion}

Acknowledging the lack of available tourism simulations, we have detailed the design, development, testing and validation of a $\mathrm{SD}+\mathrm{AB}$ game simulation designed to assist the learning of undergraduate students in relation to sustainable tourism principles, encouraging them to develop a stronger understanding of sustainable tourism management underpinned by systems thinking as per Cotterell et al.'s (2019) call for such as approach. The simulation builds on an earlier version of the game, which was itself innovative in introducing SD to a tourism simulation. Unlike many of the hospitality and management simulations that are functionally focused, the simulation at the heart of this paper has developed into a holistic game that allows students to simulate tourism development decision-making from multiple stakeholder perspectives, explicitly acknowledging the contested and differing power positions of stakeholders in the process. It also operationalises a solution to the typical conundrum of individuals assuming multiple, and sometimes conflicting, stakeholder roles by decoupling identities from individuals through the ER approach.

Validation of both versions of the simulation provides tentative evidence of its value as a teaching and learning tool. For students testing Version 1, in many cases, the game made the intended and unintended consequences of their choices relating to GE and TD investments, and rezoning of lands more evident to them, highlighting the interrelated nature of tourism destination planning. This stage of validation was also informative in suggesting potential extensions to the game, many of which have been acted upon in designing Version 2 of the simulation as detailed in this paper. Initial classroom evaluation of the combined SD $+\mathrm{AB}$ version is scheduled for 2020 using a successor subject at the same institution titled Destination Concepts, which will incorporate the advanced simulation as a tool to assist student learning. 
The current simulation extends the coastal tourism simulation of Anctil and Le Blanc (2016). Firstly, the number of variables that can be simulated in the game is substantially increased, acknowledging that Anctil and Le Blanc (2016, p. 786) note their "simulation tool was kept deliberately simple, in order to be user friendly". It also simulates various power relationships not made explicit in their study through the use of Will's (2016) flocking model.

Additionally, unlike the developing setting of Anctil and Le Blanc's work, the simulation is based on a developed destination with stagnant growth. Anctil and Le Blanc's (2016) work was also pitched more as an educational tool for industry practitioners and various stakeholders involved in tourism development decision making, whilst this tool is focused on teaching undergraduate student's sustainable tourism principles and, as such, the following teaching and learning implications of using it in the classroom are detailed.

Considering the use of the simulation as a teaching tool, the progression of the game over the 20-year time span enabled students to witness the impacts of their decisions over this extended period, and the surprise of witnessing this lag in impact reiterated the need for them to take a long term view of tourism planning. In class, students were observed to pay close attention not only to their own current and past simulated results, but also those of other groups, as all simulation results were projected in the classroom. Students' comments and discussions in deciding their next time segment planning strategy suggested that their learning was taking place through observing both their group's and others' decision-making, which is indicative that an open competition format might enhance simulation related learning by allowing students to observe the different outcomes of disparate strategies, perhaps with groups acting on behalf of competing destinations.

The use of the simulation in the classroom emphasised the importance of destination context. This context allowed students to ascribe character to the hypothetical simulated destination, developing it through careful consideration about the needs and potential of the region. It provided a mental image that students could conceive success and failure with, thereby enhancing the simulation's believability and the seriousness with which students approached the exercise. This is an important lesson for using such simulations, as context was crucial to successful teaching practice. There is also the future opportunity to more closely align the destination context explicitly with destinations illustrating different phases of the TALC model (Butler, 1980, 2006), thereby closely linking theory to simulated reality.

From a teaching perspective, the use of the simulation in a classroom setting presented a few challenges to be mindful of for effective teaching practice. Although minimal technical competence is required to operate the software, the teaching team should be sufficiently familiar with the simulation outputs to explain the meaning and implications of these to students. In this instance, all teaching staff were inducted on the use of the simulation software. The importance of the context may also lead to some difficulty in selecting a suitable tourism destination(s) that is sufficiently known to domestic and international students, but not so familiar that they could be mired in debates about minute decisions that may distract from the key variables under consideration. The teaching team should also design pre-simulation learning around increased understanding of the key variables, including the functions of DMOs and the ways in which TD investment, GE investment and land rezoning decisions could manifest in the chosen region(s). There may also be opportunities to contextualise simulation learning relative to the universal SDGs in order to illustrate to students that they are a complex network in which every goal is interlinked (Le Blanc, 2015). For example, working through the underpinning CLD depicted in Figure 1, our simulation 
links the top-level goals of Decent Work and Economic Growth (SDG 8) with Industry, Innovation and Infrastructure (SDG 9) and Sustainable Cities and Communities (11) and related lessons could be drawn based on the simulated nature of these linkages.

\subsection{Limitations \& future research}

Version 1 of the simulation drew upon the views of undergraduate students and academics from one Australian based tourism and hospitality provider. On this basis, an extended sample beyond one institution may have differently informed the design of Version 1, potentially with a broader sample suggesting a wider range of variables to simulate in the causal loop model. Version 2 is currently limited as it is yet to undergo classroom testing to determine its effectiveness as a tool for teaching sustainable tourism principles. The responses from testing of Version 1 were promising, and the enhanced precision of inputs and the enabling of multi-stakeholder perspectives of Version 2 will likely enhance these positive responses. Beyond testing this simulation again at the Australian higher education provider which hosted the first version, several other Australian higher education institutions have expressed interest in adopting and testing the simulation in their sustainable tourism courses.

In addition, as this simulation was created with undergraduates in mind, there is scope to explore the possibility of extending the application of the simulation as a teaching and learning tool across the undergraduate curriculum, scaffolding understanding of SD and sustainability concepts from first year to capstone. Close alignment with study programs would enhance the usefulness of the simulation, particularly in relation to the teaching of SD as a means of understanding sustainable tourism at the destination level. While this simulation focuses on tourism, having outlined the robust, iterative methodology for developing this teaching tool, future work could extend the development and use of such simulations into the related fields of hospitality and events, to enable the teaching of sustainable principles to be contextualised in meaningful, reality-based scenarios relevant to these fields. 


\section{References}

Anctil, Annick, and David Le Blanc. 2016. "An educational simulation tool for integrated coastal tourism development in developing countries." Journal of Sustainable Tourism 24 (5):783-798.

AQF (2013). Australian Qualifications Framework (2nd Edition), Australian Qualifications Framework Council: Adelaide, South Australia.

Balkundi, Prasad, Zoe Barsness, Judd H. Michael. 2009. "Unlocking the Influence of Leadership Network Structures on Team Conflict and Viability", Small Group Research 40:301-322. https://doi.org/10.1177/1046496409333404

Barr, Lynton G. 2015. "Around the Jetties." An Angler's Newsletter, August 2015, 1-4.

Barsade, Sigal G. 2002. "The ripple effect: Emotional contagion and its influence on group behavior." Administrative Science Quarterly 47 (4):644-675.

Benckendorff, Pierre, Gui Lohmann, Marlene A. Pratt, Paul A. Whitelaw, Paul Strickland, and Paul Reynolds. 2015. "Creating educator resources for online simulation-based pedagogies in tourism and hospitality." Paper presented at the CAUTHE 2015: Rising Tides and Sea Changes: Adaptation and Innovation in Tourism and Hospitality, Gold Coast, Queensland, February 2-5 2015.

Benckendorff, Pierre, Pauline J. Sheldon, and David R. Fesenmaier. 2014. Tourism information technology. Wallingford: CABI.

Borgatti Stephen P., and Daniel S. Halgin. 2011. "On Network Theory," Organization Science, 22:5, 1168-1181.

Borshchev, Andrei, and Alexei Filippov. 2004. "From system dynamics and discrete event to practical agent based modeling: reasons, techniques, tools." Proceedings of the 22nd International Conference of the System Dynamics Society. July 25 to 29, 2004, Oxford, UK.

Bowen, David, Shahida Zubair, and Levent Altinay. 2016. "Politics and tourism destination development The evolution of power." Journal of Travel Research 56 (6):725-743. doi: $10.1177 / 0047287516666719$.

Boyatsis, Richard E. 1998. Transforming qualitative information: Thematic analysis and code development. Thousand Oaks: Sage Publications.

Boyle, Andrea. 2017. Integrating sustainability in the tourism curriculum: dilemas and directions. In Benckendorff, P. \& Zehrer, A. (Eds). Handbook of teaching and learning in tourism (pp. 389-401). Cheltenham: Edward Elgar Publishing Ltd.

Butler, Richard W. 1980. "The concept of a tourist area cycle of evolution: implications for management of resources." The Canadian Geographer/Le Géographe Canadien 24 (1):5-12.

Butler, Richard W. 2006. The Tourism Area Life Cycle, Vol. 2: Conceptual and theoretical issues. Clevedon: Channel View Publications. 
Chen, Peter Pin-Shan. 1976. "The entity-relationship model - toward a unified view of data." ACM Transactions on Database Systems (TODS) 1 (1):9-36.

Chiu, Chia-Yen Chad, Prasad Balkundi, and Frankie Jason Weinberg. 2017. "When managers become leaders: The role of manager network centralities, social power, and followers' perception of leadership." The Leadership Quarterly 28 (2):334-348.

Cohen, Michael D., James G. March, and Johan P. Olsen. 1972. "A garbage can model of organizational choice." Administrative Science Quarterly 17 (2):1-25.

Cotter, Richard V., and David J. Fritzsche. 2010. The Business Policy Game: Player's manual. 6th ed: Prentice Hall.

Cotterell, Debbie, Robert Hales, Charles Arcodia, and Jo-Anne Ferreira. 2019.

"Overcommitted to tourism and under committed to sustainability: the urgency of teaching "strong sustainability" in tourism courses", Journal of Sustainable Tourism, 27 (7):882-902, DOI: $10.1080 / 09669582.2018 .1545777$

Douglas, Alecia, Brian Miller, Francis Kwansa, and Pamela Cummings. 2008. "Students' perceptions of the usefulness of a virtual simulation in post-secondary hospitality education." Journal of Teaching in Travel \& Tourism 7 (3):1-19.

Emerson, Richard M. 1962. "Power-dependence relations." American Sociological Review 27 (1):31-41.

Gosen, Jerry, and John Washbush. 2004. "A review of scholarship on assessing experiential learning effectiveness." Simulation \& Gaming 35 (2):270-293.

Gössling, Stefan (2017) Tourism, information technologies and sustainability: an exploratory review, Journal of Sustainable Tourism, 25(7): 1024-1041.

Gregor, Shirley, and Alan R Hevner. 2013. "Positioning and presenting design science research for maximum impact”, MIS Quarterly 37 (2):337-355.

Hevner, Alan R., Salvatore T. March, Jinsoo Park, and Sudha Ram. 2004. "Design research in information systems research." MIS Quarterly 28:75-105.

Hodas, Nathan O., and Kristina Lerman. 2014. "The simple rules of social contagion.” Science Reports 4:4343. https://doi.org/10.1038/srep04343

Koeslag, Mieke, Kreune Piet Van den Bossch, Michael Hoven, Marcel Van der Klink, and Wim Gijselaers. 2018. "When Leadership Powers Team Learning: A Meta-Analysis", Small Group Research 49 (4): 475- 513.

Kolb, David A. 1984. Experiential Learning as the Science of Learning and Development. Englewood Cliffs, NJ: Prentice Hall.

Larréché, Jean-Claude, Hubert Gatignon, and Rémi Triolet. 2010. Markstrat by STRATX: Participant Handbook: STRATX International.

Le Blanc, David. 2015. "Towards Integration at Last? The Sustainable Development Goals as a Network of Targets", Sustainable Development 23 (3): 176-187. 
Leiper, Neil. 1998. "Tourism and Tourism Systems". Occasional Paper No. 1, Department of Management Systems. Palmerston North: Massey University.

Maani, Kambiz, and Robert Y Cavana. 2000. Systems thinking and modelling:

Understanding change and complexity. UK: Prentice Hall.

McCarthy, William E. 1982. "The REA accounting model: A generalized framework for accounting systems in a shared data environment." Accounting Review:554-578.

McGrath, G Michael, and Elizabeth More. 2001. "The Greta system: Organizational politics introduced to the garbage can." Decision Support Systems 31 (2):181-195.

McGrath, G. Michael, Madelene McWha, Leonie Lockstone-Binney, Faith Ong, Paul A. Whitelaw, and Elisabeth Wilson-Evered. (2019). Towards an AQF-Based Template for the Design and Development of T\&L Simulations and Games, Proceedings of CAUTHE 2019, 11-14 February, Cairns, Australia.

Morrison, Alastair M. 2013. Marketing and managing tourism destinations. UK: Routledge.

Moyle, Brent D., Char-lee McLennan, Lisa Ruhanen and Betty Weiler. 2014. "Tracking the concept of sustainability in Australian tourism policy and planning documents", Journal of Sustainable Tourism, 22 (7):1037-1051, DOI: 10.1080/09669582.2013.839694

Newman, M. 2010. Networks: An introduction. Oxford, UK: Oxford University Press.

OLT. 2017a. "Case Studies." Australian Government Office for Learning and Teaching, accessed 19 April. https://www.bizsims.edu.au/case-studies.

OLT. 2017b. "A-Z Index of Simulations." Australian Government Office for Learning and Teaching, accessed 19 April. https://www.bizsims.edu.au/a-z-index-simulators.

Pfeffer, Jeffrey. 1981. Power in organizations. MA, USA: Pitman Marshfield.

Phelan, Liam, Bonnie McBain, Anna Ferguson, Valerie Brown, Iain Hay, Richard Horsfield, and Ros Taplin. 2015. "Learning and teaching academic standards statement for environment and sustainability". Sydney: Office for Learning and Teaching. Retrieved from:

http://environmentltas.gradschool.edu.au/uploads/content/drafts/ES_LTAS_Statement_Final. pdf

Pressman, Roger S. 2005. Software engineering: A practitioner's approach. London: McGraw Hill.

Schianetz, Karin, and Linda Kavanagh. 2008. "Sustainability Indicators for Tourism Destinations: A Complex Adaptive Systems Approach Using Systemic Indicator Systems", Journal of Sustainable Tourism, 16 (6):601-628, DOI: 10.1080/09669580802159651

Schott, Christian, and Stephen Marshall. 2018. Virtual reality and situated experiential education, Journal of Computer Assisted Learning 34(6):843-852.

Scott, Noel, Rodolfo Baggio, and Chris Cooper. 2008. Network analysis and tourism: From theory to practice. Clevedon: Channel View Publications. 
Senge, Peter M. 1990. The Fifth Discipline: The Art and Practice of the Learning Organization. Milsons Point, NSW: Random House.

Singh, Anil, George Mangalaraj, and Aakash Taneja. 2010. "Bolstering teaching through online tools." Journal of Information Systems Education 21 (3):299-311.

Suhay, Elizabeth. 2016. "Political conformity: Evidence and mechanisms." Draft prepared for Political Persuasion Conference, 9-10 January 2016, Laguna Beach, CA.

Tourism Victoria. 2015. "Gippsland, Market Profile: Year ending December 2014." Tourism Victoria, accessed 24 Feb 2017. http://www.tourism.vic.gov.au/research/domestic-andregional-research/regional-visitation.html.

United Nations. 2015. "Transforming our World: The 2030 Agenda for Sustainable Development." New York: United Nations.

UNWTO. 2013. "Sustainable Tourism for Development Guidebook.” Madrid: UNWTO.

Visit Victoria. 2017. "Overview - Lakes Entrance." Visit Victoria, accessed 24 Feb 2017. http://www.tourism.vic.gov.au/research/domestic-and-regional-research/regionalvisitation.html.

Will, Thomas E. 2016. "Flock leadership: Understanding and influencing emergent collective behavior." The Leadership Quarterly 27 (2):261-279. 


\section{Figures}

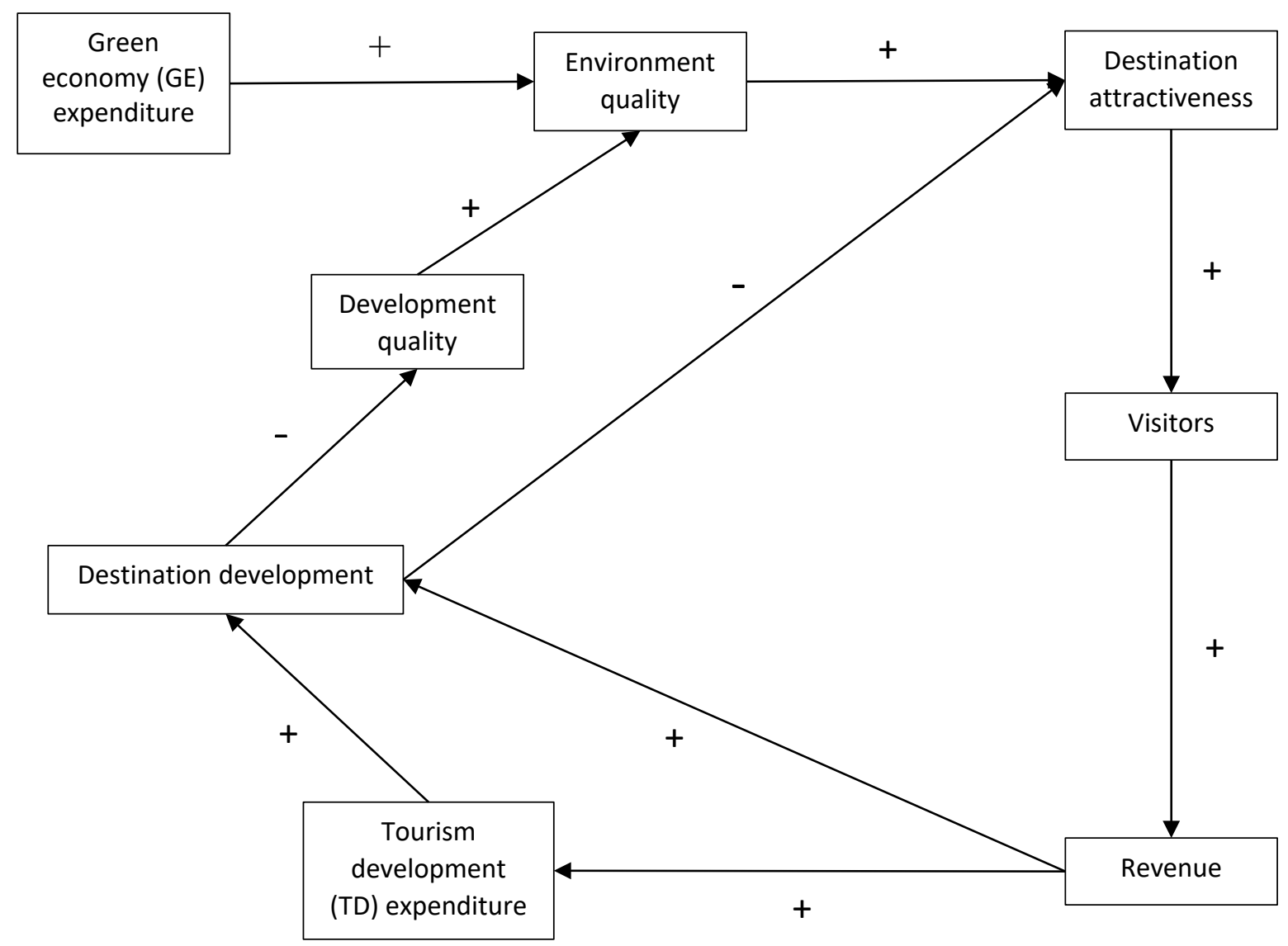

Figure 1: Game CLD central model 


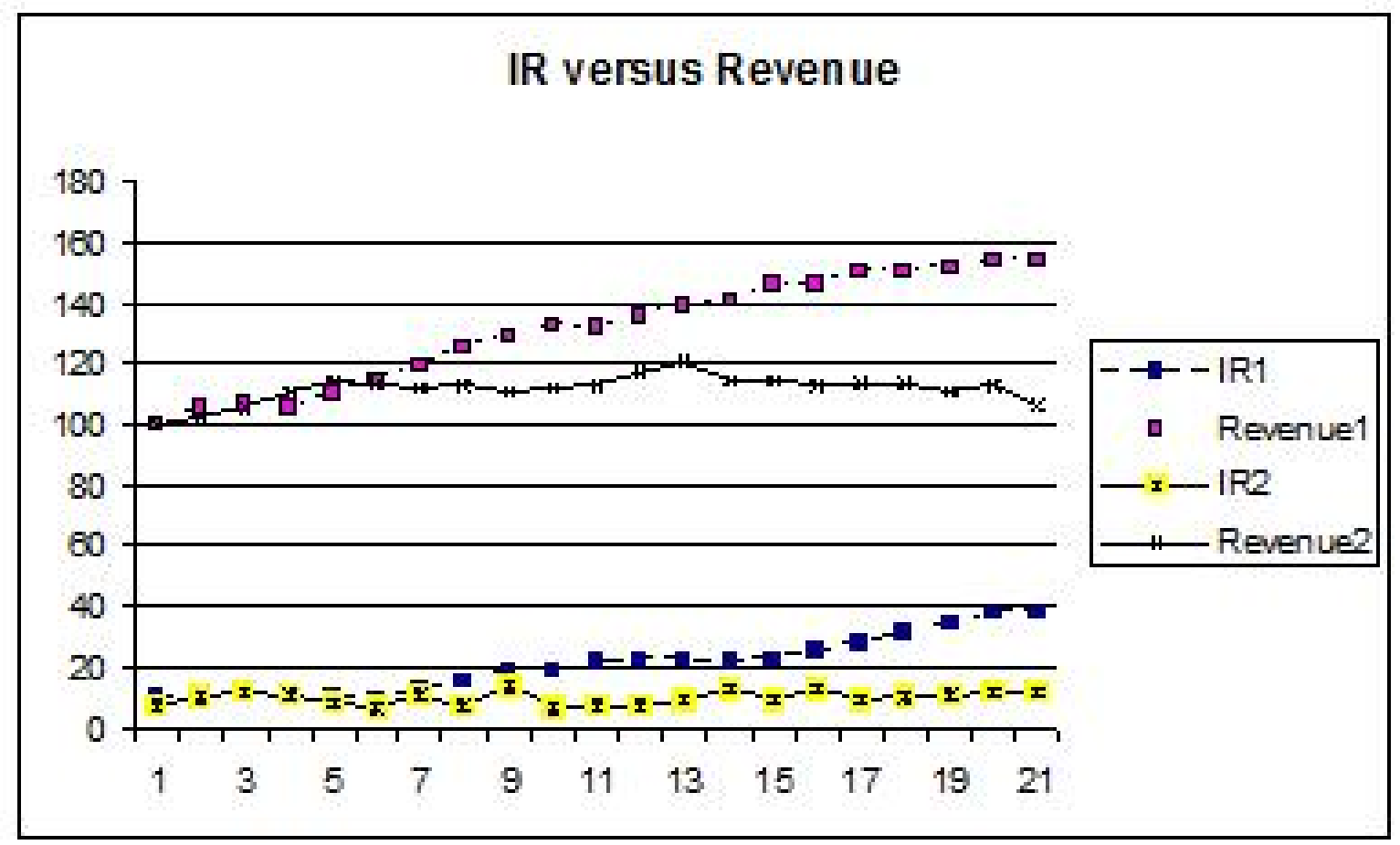

Figure 2: Annual revenue versus two different GE/total investment ratio (IR) patterns 